\title{
Significance of YogasanasAnd Exercises In Pregnancy
}

\author{
${ }^{1}$ Dr. Smita Sarmah, ${ }^{2}$ Dr. Balen Baishya \\ ${ }^{1}$ PG Scholar , ${ }^{2}$ Professor \& Ex-Head of Dept. Of Prasuti Tantra\&StreeRoga Govt. Ayurvedic College, \\ Jalukbari Guwahati-14, Assam
}

\begin{abstract}
:
Pregnancy is a state of emotion. During pregnancy period,mind will be filled with both positive as well as negative thoughts. Those thoughts affect the mother as well as the fetus.Positive thoughts will bring happiness to the fetus through mother and negative thoughts will bring sorrow, grief to the fetus through mother.So, the environment where the lady spend her time, daily routine of the lady, food that is taken by the lady are very important.

Yogasanas and exercises not only helpful for the maintenance of health of the pregnant lady and the fetus but also helpful for easy labour by relaxing the body. Yogic practices integrate body, mind and spirit. Yogasanas bring harmony, develop a satisfied and positive attitude towards life. It helps to build immunity, inner strength, improve control over body and mind. Practicing yogasanasand exercises calm mind of the pregnant lady and prepare the body for the extreme changes that she will go through in the coming months. It helps the pregnant lady to deal with all the physical and emotional changes with ease.
\end{abstract}

Keywords: Pregnancy, fetus, yogasanas, exercises

\section{Introduction:}

Pregnancy is a state which needs physical and social adaptation. During the pregnancy period, pregnant lady go through some positive as well as negative thoughts. She may have some anxiety regarding labour pain and foetal outcome. Those thoughts affect the mother as well as the foetus. Pregnant woman's health has become the prime concern in present era. Physical as well as mental health of a pregnant lady is very important for normal growth and development of foetus.

Yoga is an ancient discipline designed to bring balance and health to the physical,mental,emotional and spiritual dimensions of the individual.The primary aim of yoga is to restore the mind to simplicity and peace, to free it from confusion and distress. This sense of calm comes from the practice of yogic asanas and pranayam. Unlike other form of exercises which strain muscles and bones, yoga gently rejuvenates the body ${ }^{1}$.Yogic practices integrate the body,mind and spirit. They bring harmony; develop a satisfactory and positive attitude towards life. It helps to build immunity, inner strength, improves control over body and mind. Regular practice of yogasanas during pregnancy stabilizes the body and mind of the pregnant lady.Yogasanashelp to get rid off various ailments faced by women during pregnancy. It has effects in reduction of high blood pressure, weight controland emotional factors and in better maintenance physical and emotional state ${ }^{2}$.

\section{Aim and Ojectives:}

To study about the significance of yogasanasand exercises in prengnancy. 
${ }^{1}$ Dr. Smita Sarmah, International Journal of Ayurvedic\& Herbal Medicine 7(6) Nov.-Dec. 2017 (2935-2938)

\section{Description:}

Yoga provides a great range of activity to unborn child and mother by numerous ways. Yogasanas or yogic postures are typical physical postures of the body where in different muscles get simultaneously stretched and relaxed. Yogasanas recondition body and mind to bring the highest possible muscular tone, mental health.In yogic postures, muscular tonic reflexes occur through the stimulation of nerve endings and tonic postures are maintained. They being fixed postures, the energy expenditure is minimum with minimum stress. Yogic postures are rather tonic with diminution of muscular activity and maximum possible voluntarily induced muscular relaxation.A series of such exercises result in a state of mental calmness and one feels fresh and steady. Constipation,dyspepsia, hypertension, flatulence, backache, mental tension are the general minor problem which are faced by most of the pregnant ladies. Most of them are relieved by practicing yogasanas. Various asanas create more space in pelvis which eases the expulsion of foetus.Pranayam( breathing technique) is alsohelpful in pregnancy.It works on both mind and body .It provides extra oxygen to body by which it improves emotional stability and helps to eliminate anxiety, fear and phobia ${ }^{3}$.

Different types of yogasanas can be advised for pregnant lady. Some of the common yogasanas are:

Yogasanas

\begin{tabular}{|l|l|}
\hline \multicolumn{1}{|c|}{ Vajrasana $^{4}$} & $\begin{array}{l}\text { Functions of the reproductive organs are improved. } \\
\text { Useful for meditation. } \\
\text { Beneficial in stiff ankles and knee joints. } \\
\text { Abdominal discomfort after heavy meal is reduced and digestion is helped }\end{array}$ \\
\hline Bhadrasana $^{5}$ & $\begin{array}{l}\text { It strengthens the hip, thigh and buttocks. } \\
\text { It is good for developing flexibility of the legs. }\end{array}$ \\
\hline Marjariasana $^{6}$ & $\begin{array}{l}\text { Give flexibility to the spine. } \\
\text { Improves digestion. } \\
\text { Improves blood circulation. } \\
\text { Relaxes the mind. } \\
\text { Releases back pain }\end{array}$ \\
\hline Tadasana $^{6}$ & Help to develop physical and mental balance. \\
\hline Ardhatitli asana $^{6}$ & $\begin{array}{l}\text { It helps in loosening of hip, knee joints, which is required for faster and } \\
\text { easy delivery. }\end{array}$ \\
\hline Pavanmuktasana $^{7}$ & $\begin{array}{l}\text { This asana removes the poisonous gas from the abdomen and helps to } \\
\text { cure indigestion, acidity, flatulence etc. } \\
\text { it helps in removing constipation. }\end{array}$ \\
\hline Trikonasana & $\begin{array}{l}\text { It makes the spine flexible and maintain the youth of the body. } \\
\text { The increased circulation that takes place in the region of the spine, } \\
\text { naturally tones up all the nerves and muscles . }\end{array}$ \\
\hline
\end{tabular}

\section{Pranayam:}

Pranayam has a greater beneficial effect on the body. Pranayam word consists of prana (breath of life) and ayama (expansion). It is an important method that gives tone to lungs, heart, increases the capacity of lungs and thus help the body to get more oxygen ${ }^{9}$. It is useful in pregnancy as it can provide more oxygen towards mother as well as to the foetus. Fetus get everything from mother so, mother has to be very strong enough.

\section{Exercises in pregnancy ${ }^{10}$ :}

Now a days, the aerobic and strength training during pregnancy is recommended as it is known that by exercising during pregnancy there is: 
${ }^{1}$ Dr. Smita Sarmah, International Journal of Ayurvedic\& Herbal Medicine 7(6) Nov.-Dec. 2017 (2935-2938)

No increase in early pregnancy loss.

No late pregnancy complication.

No abnormal fetal growth.

No adverse neonatal outcomes.

\section{Benefits of exercises during pregnancy ${ }^{10}$ :}

Strengthens muscles needed for labour and delivery.

Helps toreduce backache, constipation, bloting and swelling.

Improves postures.

Gives energy and improves mood.

Lessens some of the discomforts in pregnancy.

Helps one to feel less tired and sleep better.

Increases strength and stamina.

Infants have less body fat at birth.

Greater neurodevelopmental scores.

\section{Discussion:}

Exercise and yogasanas are helpful in a pregnant woman. During pregnancy with the advancement of months, gravid uterus gives pressure on the abdominal muscles as well as on the other structures like urinary bladder, rectum, diaphragm also. Regular use of exercises and yogasanas help abdominal muscles to become stretchable. We can see a simple example, if we spend our time by only doing work in a sitting manner, then at last we feel tired. But if we do regular exercise or yogasanas, then we feel light and can do the work in a easy manner. Like that, a pregnant lady if do these practices in a regular manner then it will make her body light and also gives a positive attitude towards her upcoming time from labour pain to give birth a baby. Pranayam also very helpful in making a pregnant lady stressfree by giving her positive vibes from the surrounding. So, pregnant lady should be encouraged to do yogasanas and exercises in a regular basis under the guidance of experts.

\section{Conclusion:}

Precautions should be taken while practicing yogasanas is very important.

During practicing yogasana and exercises by pregnant lady, an advice from expert should be taken for avoiding the untoward effects.

During pregnancy period, when women are battling mood swings at varing levels, fatigue and sickness.practice of yogasana and exercises ease all such conditions ensuring a period of relieved nine months followed by an easier labour and smooth delivery.

This way, one can keep themselves fit and stable during pregnancy and get relief from anxiety and stress of pregnancy.

\section{Reference:}

1. B.K.S. Iyengar ,Iyengar Yoga for beginners, Dorling Kindersley, Reprint-2006, Chapter no-1, Page no-9.

2. The yoga science for everyone by Dr. Ravi R Javalgekar

3. The yoga science for everyone by Dr. Ravi R Javalgekar

4. Sukhayu wellness magazine for all

5. yogic therapy by srimata swami shivanandasaraswati, 9th edition, Umachalprakashani, chapter 7, yoga exercises for pregnant mother, pg no-462,245)

6. Sukhayu wellness magazine for all 
${ }^{1}$ Dr. Smita Sarmah, International Journal of Ayurvedic\& Herbal Medicine 7(6) Nov.-Dec. 2017 (2935-2938)

7. yogic therapy by srimata swami shivanandasaraswati, 9th edition, Umachalprakashani, chapter 7, yoga exercises for pregnant mother, pg no-462,279)

8. yogic therapy by srimata swami shivanandasaraswati, 9th edition, Umachalprakashani, chapter 7, yoga exercises for pregnant mother, pg no-462,290)

9. yogic therapy by srimata swami shivanandasaraswati, 9th edition, Umachalprakashani, chapter 7, yoga exercises for pregnant mother, pg no-462,314)

10. Donald school manual of practical problems in obstetrics (by NarendraMalhotra, RandhirPuri, JaideepMalhotra) edition-2012, Jaypee brothers medical publishers (P) LTD, page no- 641 